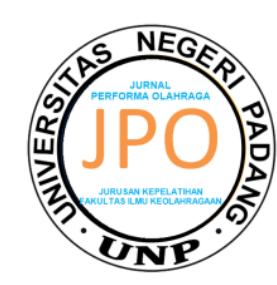

\title{
PENGARUH LATIHAN PLYOMETRICS TERHADAP PENINGKATAN KEMAMPUAN THREE POINT SHOOT
}

\author{
Muhammad Ghibran Jalil ${ }^{1}$, Adnan Fardi ${ }^{2}$, John Arwandi ${ }^{3}$, Ronni Yenes ${ }^{4}$ \\ ${ }^{1}$ Fakultas Ilmu Keolahragaan, Universitas Negeri Padang, Indonesia
}

\section{Informasi Artikel}

Diterima 2020-11-23

Direvisi 2020-02-06

Dipublikasikan 2021-03-06

\section{Keyword:}

Plyometrics Training Three Point Shoot Ability

\begin{abstract}
The problem in this research is the lack of the three point shoot ability of the male athlete Dharma Muda Dharmasraya. The variables in this study were plyometrics exercise and the ability of the three point shoot. The purpose of this study was to determine the effect of plyometrics training on the improvement of the three point shoot ability of male athletes Dharma Muda Dharmasraya. This type of research is a pre-experiment which aims to see the effect of plyometrics training on the improvement of the three point shoot ability. The population in this study were all male basketball athletes, Dharma Muda Dharmasraya, totaling 17 people. Sampling was done by purposive sampling technique, namely male athletes Dharma Muda Dharmasraya as many as 10 people. To obtain research data, the three point shoot ability test was used. The data obtained were analyzed by using the t test. Based on the results of data analysis, it is known that plyometrics training has a significant effect on the improvement of the three point shoot ability. Where the pre-test average of the three point shoot ability was 16.1 while the post test increased to 22.8. Then obtained the mean difference test ( $t$ test) of $t$ count 10.30 while $t$ table 2.26 with a significant level $\alpha=0.05$ and $n=$ 10 , then $t$ count $>t$ table $(10.30>2.26)$, it can be concluded that There is a significant effect of the form of plyometrics training on the improvement of the three point shoot ability of the male athlete Dharma Muda Dharmasraya.
\end{abstract}

(C) 2020 The Authors. Published by Universitas Negeri Padang. This is an open access article under the CC BY-NC-SA license (https://creativecommons.org/licenses/by-nc-sa/4.0/

\section{Penulis Korespondensi:}

Muhammad Ghibran Jalil, Universitas Negeri Padang Email: gibranjalil58@gmail.com

\section{PENDAHULUAN}

Pada era modern ini, pendekatan secara ilmiah dalam meningkatkan mutu prestasi olahraga sangatlah penting, terlebih bicara tentang olahraga khususnya pada olahraga prestasi.Olahraga prestasi yang berkembang saat ini beragam, mulai dari olahraga yang bersifat perorangan maupun olahraga yang bersifat kelompok atau olahraga beregu.Kemajuan ilmu dan teknologi menimbulkan perubahan yang cepat dalam berbagai tatanan kehidupan manusia, sehingga terjadinya globalisasi dan pasar bebas, (Ridwan, M., \& Irawan, R 2018).Olahraga prestasi yang dimaksud dalam perkembangan sekarang ini adalah olahraga kompetitif seperti cabang Olahraga Bolabasket, Bolavoli, Sepakbola, Tennis, Bulutangkis, Tinju, Renang dan lain-lain 
sebagainya.Kegiatan olahraga banyak faktor pendukung yang mempengaruhi untuk mendapatkan prestasi, seperti; kondisi fisik, teknik, taktik, dan mental, Soniawan, V., \& Irawan, R (2018). Prestasi olahraga yang dicapai merupakan hasil akumulatif dari berbagai aspek usaha, di samping itu juga untuk mewujudkan prestasi olahraga memerlukan suatu proses yang relatif lama di antaranya melalui training atau latihan.

Latihan (training) diartikan oleh Palar, C. M., Wongkar, D., \& Ticoalu, S. H. (2015) bahwa latihan didefinisikan sebagai aktivitas olahraga secara sistematis yang dilakukan berulang-ulang dalam jangka waktu lama disertai dengan peningkatan beban secara bertahap dan terus- menerus sesuai dengan kemampuan masing-masing individu, tujuannya adalah untuk membentuk dan mengembangkan fungsi fisiologis dan psikologis. Menurut (Mardela, R., 2019) latihan merupakan suatu kegiatan yang dikembangkan untuk mempersiapkan kondisi fisik dengan tujuan meningkatkan potensi kemampuan biomotorik atlet ke tingkat yang lebih tinggi. Latihan adalah proses kerja yang dilakukan secara sistematis dan berkesinambungan. Beban atau intensitasnya semakin hari semakin bertambah agar memberikan rangsangan secara menyeluruh terhadap tubuh.

Menurut Khlifa, R., Aouadi, R., Hermassi, S., Chelly, M. S., Jlid, M. C., Hbacha, H., \& Castagna, C. (2010) Basketball adalah olahraga tim multifaset yang membutuhkan kebugaran anaerobik yang berkembang dengan baik untuk dimainkan dengan sukses. Bolabasket merupakan permainan dengan gerakan yang kompleks yaitu gabungan dari jalan, lari dan lompat serta unsur kekuatan, kecepatan, ketepatan, kelentukan, keseimbangan dan lain-lain (Wulandari, M., \& Umar, U. 2020).Artinya gerakan-gerakan yang dibutuhkan dalam bermain bolabasket merupakan gabungan dari unsur-unsur gerakan yang saling menunjang dan untuk menampilkan gerakan-gerakan tersebut sangat bergantung kepada penguasaan teknik-teknik dasar yang menunjang permainan ini. Dengan teknik dasar yang baik dan benar maka efisiensi dan efektifitas gerak akan dicapai yang selanjutnya akan membuahkan keterampilan yang berkualitas.

Gerakan yang efektif dan efisien dalam permainan bolabasket merupakan suatu tujuan dalam penguasaan teknik dasar yang baik. Menurut Oktavianus, I., Bakhtiar, S., \& Bafirman, B. (2016) beberapa teknik dasar yang perlu diketahui dalam permainan Bolabasket adalah sebagai berikut: (a) Passing (teknik melempar dan menangkap bola); (b) Dribling (teknik menggiring bola); (c) Shooting (teknik menembak); (d) Pivot (berputar badan dengan salah satu kaki sebagai poros); (e) Foot work (teknik pergerakan kaki); (f) Jumping (melompat); (g) Rebounding (teknik merayah bola); (h) Intercept (teknik memotong arah passing bola); (i) Steals (teknik merebut bola). Secara garis besar bahwa teknik dasar bermain Bolabasket terdiri dari: (a) Passing (mengoper); (b) Dribbling (menggiring); (c) Shooting (menembak); (d) Rebounding (merayah). Shooting dalam permainan bolabasket adalah salah satu teknik menembakkan bola ke jaring lawan (DZUL FIKRI, M. U. H. A. M. M. A. D., 2013). Kemenangan suatu tim ditentukan dari seberapa bisa mereka bekerja sama dengan baik (Ramos, M., Yenes, R., Donie, D., \& Oktavianus, I., 2020). Dalam bolabasket teknik ini paling banyak untuk mencetak angka dan menentukan kemenangan dalam pertandingan, sebab kemenangan sangat ditentukan oleh banyaknya bola yang masuk ke ring basket. Menurut Margono, M., Yagusta, R. A. B., \& Khuzaini, A. (2018) menjelaskan gerakan yang baik menimbulkan efisiensi kerja dan dengan latihan yang teratur dapat menjadikan gerakan menjadi lebih baik dan efektif.

Menurut Donie, D (2019) Setiap atlet bolabasket yang mempunyai daya ledak otot tungkai yang baik tentunya mereka dapat melakukan kemampuan jump shoot dengan baik dan lawan akan kesulitan untuk merebut bola. Selain itu, daya ledak otot atau power sangat berperan penting karena dapat meningkatkan kemampuan otot tungkai maupun otot tangan yang sangat 
dibutuhkan, salah satunya dalam three point shoot. Three point shoot merupakan salah satu jenis tembakan tiga angka (Fernando, A., \& Yenes, R, 2020). Menurut Malta (2019) tembakan ini biasanya hanya dilakukan di luar garis three point. Dalam melakukan tembakan three point shoot dibutuhkan teknik yang halus dan berirama serta mekanisme tubuh yang baik. Menurut DZUL FIKRI, M. U. H. A. M. M. A. D. (2013)three point shoot adalah tembakan yang menghasilkan point tertinggi dalam permainan bolabasket. Lebih lanjut Three point shoot merupakan sesuatu yang sangat penting dalam pertandingan, kemampuan untuk menembak akan membantu menambah skor dalam permainan.

Banyak bentuk latihan yang digunakan untuk meningkatkan kemampuan otot tungkai dan otot tangan, akan tetapi pola latihan plyometrics adalah salah satu bentuk latihan yang dapat digunakan dalam olahraga bolabasket. Salah satu bentuk latihan atau teknik latihan yang harus dilakukan bila kita ingin meningkatkan power otot tungkai maupun power otot tangan adalah dengan latihan plyometrics. Menurut Lockie, R. G., Murphy, A. J., Callaghan, S. J., \& Jeffriess, M. D. (2014) Pelatihan plyometrics dapat memberikan penekanan yang lebih besar pada produksi gaya berdiri, dengan latihan seperti melompat dan melompat menghasilkan gaya reaksi tanah (GRF) yang jauh lebih besar jika dibandingkan dengan lari cepat maksimal. Latihan plyometrics adalah salah satu latihan yang dilakukan untuk menghasilkan kemampuan daya ledak otot tungkai atau otot lengan (Nuryadi, A., 2016).Latihan plyometrics merupakan latihan dengan memanfatkan berat badan sendiri atau menggunakan beberapa alat untuk merangsang latihan. Latihan plyometrics terdiri dari bermacam-macam bentuk pembebanan latihan (DARI, L. J. G. J. D., TUNGKAI, D. L. O., \& BASUKI, S., 2016). Latihan plyometrics dilakukan untuk mengembangkan power bisa dengan cara mengembangkan kecepatan memelihara kekuatan atau mengembangkan kekuatan dan memelihara kecepatan. Lebih lanjut menurut Dinata, N (2019) Latihan plyometrics merupakan suatu bentuk latihan yang umum digunakan untuk meningkatkan kemampuan daya ledak otot (power) otot tungkai.Latihan plyometrics bertujuan untuk meningkatkan kecepatan dan kekuatan. Adapun pedoman pelaksanaan latihan plyometrics antara lain: (1) Pemanasan dan pendinginan, (2) Intensitas tinggi, (3) Beban gerak progresif, (4) maksimalkan kekuatan dan minimalkan waktu, (5) Jumlah pengulangan yang optimal, (6) Istirahat yang teratur, (7) Membangun dasar yang tepat, (8) Mengindividukan program latihan. Agar pelaksanaan latihan bisa berjalan efektif, seorang pelatih harus menyusun periodesasi latihan yang tepat, seorang pelatih harus menyusun periodesasi latihan yang tepat.atlet melakukan set latihan plyometric di lapangan, mengikuti set latihan ketahanan di ruang angkat beban. Karakteristik organisasi dari metodologi ini memungkinkan pelatih untuk dengan mudah mengawasi latihan beban dan plyometrics dalam satu latihan pada hari yang sama (Santos, E. J., \& Janeira, M. A., 2008). Meskipunplyometrics dapat menjadi metode pelatihan yang efektif untuk meningkatkan kekuatan otot, kecepatan, dan kelincahan, mekanisme yang tepat di mana plyometrics dapat menurunkan risiko cedera lutut dan meningkatkan plyometrics dalam tim pemain bolabasket masih kurang dipahami. Namun demikian, tidak ada studi yang berfokus pada analisis program plyometrics tertentu yang dilaksanakan pramusim untuk meningkatkan kinerja pada pemain bolabasket (Asadi, A., de Villarreal, E. S., \& Arazi, H., 2015).Berdasarkan kutipan di atas dapat disimpulkan bahwa latihan plyometrics merupakan latihan yang dilakukan untuk meningkatkan daya ledak otot yang sangat dibutuhkan dalam beberapa cabang olahraga, terkhususnya bolabasket.

Komponen fisik yang mengarah kepada teknik three point shoot berdasarkan kebutuhan pada penelitian ini adalah daya ledak otot. Afrizal (2018) berpendapat bahwa daya ledak otot merupakan komponen kondisi fisik yang sangat perlu diperhatikan oleh pelatih dalam meningkatkan prestasi atlet. Menurut Maidarman, M (2017) daya ledak otot mempunyai peranan penting dalam cabang olahraga yang membutuhkan kontraksi otot yang kuat dan cepat. Daya 
ledak otot merupakan perpaduan antara kekuatan dan kecepatan.Ihsan, N., Zulman, Z., \& Adriansyah, A. (2018) mengatakan bahwa daya ledak otot merupakan kemampuan untuk menghasilkan kekuatan maksimal dan kecepatan maksimal explosive dalam waktu yang cepat dan sesingkat-singkatnya sesuai dengan apa yang diinginkan. Kekuatan dibutuhkan pada lengan agar kuat memegang bola serta dibutuhkan dorongan lengan dan jari-jari telapak tangan dalam melempar bola serta pada target ring basket juga di dukung dengan tolakan atau lompatan ke dua kaki dalam mendukung hasil lemparan yang memiliki akurasi yang tepat sasaran. Daya ledak otot dalam penelitian ini masuk pada jenis plyometrics yang diarahkan pada lengan dan tungkai/kaki.Plyometrics merupakan salah satu jenis latihan dalam mengembangkan daya ledak otot/power yang dapat dilatih dengan beban tubuh sendiri ataupun menggunakan beban luar yang dapat dilakukan secara efektif dan efisien.

Untuk dapat melakukan three point shoot dengan sukses tidak hanya mengandalkan teknik yang bagus saja, tetapi harus didukung dengan kondisi fisik dan psikis yang bagus karena faktor tersebut yang dapat membuat faktor teknik menjadi lebih sempurna, contohnya membentuk daya ledak otot (Power), Karena dalam olahraga tersebut dibutuhkan kecepatan berpindah gerak dari satu titik ke titik yang lain, juga kekuatan untuk menembakkan bola ke arah ring dengan tepat (Leksono, I. A. R. A., Saichudin, S., \& Januarto, O. B., 2016). Selain itu, dengan jarak menembak three point yang cukup jauh juga menjadi alasan kenapa daya ledak otot (power) sangat dibutuhkan dalam melakukan three point shoot. Padahal Ardigò, L. P., Kuvacic, G., Iacono, A. D., Dascanio, G., \& Padulo, J. (2018) mengatakan performa tembakan tiga poin adalah salah satu penentu kemenangan utama dalam bolabasket elit. Menjaga akurasi 3S persen yang tinggi (3S\%), terutama selama menit-menit terakhir close game, terbukti menjadi kunci sukses. Maka dari itu, kualitas daya ledak otot tungkai dan daya ledak otot lengan yang baik menjadi faktor yang berpengaruh terhadap keberhasilan three point shoot atlet tersebut.

Wadah pembinaan Bolabasket adalah sarana pembinaan Klub bolabasket yang tersedia di masing-masing Kota atau Kabupaten.Menurut Yenes, R., Syahara, S., \& Kiram, Y. (2018) ada tiga manfaat dari permainan bolabasket yaitu fisik, mental dan juga sosial karena banyaknya ivent yang bersifat kompetisi baik lokal maupun internasional. Melalui kegiatan latihan yang intensif, diharapkan dapat mencapai prestasi yang sangat cemerlang baik di kancah nasional maupun internasional. Di Kabupaten Dharmasraya terdapat Klub bolabasket yaitu Dharma Muda, Klub ini masih minim mengikuti kejuaraan antar Klub yang ada di Sumatera Barat, tetapi Klub Dharma Muda ini pernah mengikuti beberapa kejuaraan diantaranya yaitu pada tahun 2015 dan berhasil memperoleh peringkat ke-tiga. Kemudian pada tahun 2019 hanya mampu memperoleh peringkat ke-empat. Berdasarkan pengamatan peneliti pada saat mengikuti kejuaraan tersebut tepatnya pada pertandingan perebutan tempat ke-tiga Kejurda U-20 pertengahan tahun 2019 yang diadakan di Kabupaten Sijunjung, Tim junior putra Dharma Muda Dharmasraya ini sering melakukan three point shoot, akan tetapi three point shoot field goals atlet masih rendah yaitu dengan persentase sebesar 31,2\%. Lebih jelas lagi, perhatikan tabel data three point shoot atlet putra Dharma Muda Dharmasraya sebagai berikut:

Tabel 1. Data Three Point Shoot

\begin{tabular}{|c|c|c|c|c|}
\hline No & Nama & $\begin{array}{c}\text { Percobaan } \\
\text { Three Point } \\
\text { Shoot }\end{array}$ & $\begin{array}{c}\text { Three Point } \\
\text { Shoot Yang } \\
\text { Berhasil }\end{array}$ & $\begin{array}{c}\text { Three Point } \\
\text { Shoot Yang } \\
\text { Airball }\end{array}$ \\
\hline 1 & Arif Budiman & - & - & - \\
\hline 2 & Angges Arfiandi & 5 & 2 & 2 \\
\hline
\end{tabular}




\begin{tabular}{|c|c|c|c|c|}
\hline 3 & Bobi Saputra & 3 & 1 & 2 \\
\hline 4 & Ardi Mairanda & 2 & 1 & 1 \\
\hline 5 & Rheval & 1 & - & - \\
\hline 6 & Farhan Saputra & - & - & - \\
\hline 7 & Raken Zulfa S & 2 & - & 1 \\
\hline 8 & Andri & - & - & - \\
\hline 9 & Fadhil & - & - & - \\
\hline 10 & Julio Wibisono & 1 & - & 0 \\
\hline 11 & M Putra Rinadi & 2 & 1 & 1 \\
\hline 12 & Gugus Herdian & - & - & - \\
\hline & Total & 16 & 5 & 7 \\
\hline & Field Goals & $100 \%$ & $31,2 \%$ & $43,75 \%$ \\
\hline
\end{tabular}

Rendahnya field goals three point shoot oleh atlet Dharma Muda Dharmasraya disebabkan karena persentase dari bola hasil three point shoot yang tidak menyentuh ring lawan (air ball) lebih besar daripada persentase bola yang masuk ke ring yaitu dengan persentase sebesar $43,75 \%>31,2 \%$ serta akurasithree point shoot yang tidak tepat oleh atlet karena jarak tembakan three point shoot yang cukup jauh daripada tembakan lainnya. Melihat kenyataan ini maka dapat dilihat bahwa rendahnya kemampuan daya ledak otot tungkai dan daya ledak otot tangan menjadi salah satu faktor penghambat bagi atlet untuk menciptakan skor lewat three point shoot.

\section{METODE}

Jenis Penelitian

Penelitian ini merupakan penelitian pra eksperimen yang dilakukan terhadap atlet bolabasket putra Dharma Muda Dharmasraya.

Waktu dan Tempat Penelitian

Penelitian ini dilaksanakan empat kali dalam satu minggu di lapanganbolabasket Klub Dharma Muda di Koto Baru Dharmasraya, penelitian berlangsung pada bulan Juli sampai dengan Agustus 2020.

\section{Rancangan Penelitian}

Rancangan dalam penelitian ini yaitu menggunakan One Group Pre test Post test Design, rancangan ini terdiri dari satu kelompok (tidak ada kelompok kontrol).

Populasi dan Sampel Penelitian

Populasi dalam penelitian ini adalah seluruh atlet putra Dharma Muda Dharmasraya yang bejumlah 17 orang. Sampel pada penelitian ini adalah atlet junior putra Dharma Muda Dharmasraya yang berumur 16-18 tahun yang akan dipersiapkan untuk seleksi porprov Sumatera Barat tahun 2020 yaitu sebanyak 10 orang, dengan teknik purposive sampling.

Instrumen dan Teknik Pengumpulan Data

Instrument tes yang digunakan dalam penelitian ini adalah tes akurasi three point shoot (Oktavianus, 2016) sebanyak 15 kali tembakan.Hasil yang dicatat adalah bola hasil three point 
shoot yang masuk diberi nilai 3, bola hasil three point shoot yang tidak masuk (hanya menyentuh ring) diberi nilai 1 , dan bola hasil three point shoot yang tidak masuk (tidak menyentuh ring/airball) diberi nilai 0.

\section{Teknik Analisis Data}

Teknik analisis data statistik yang digunakan dalam penelitian ini adalah uji normalitas liliefors dan uji $\mathrm{t}$ dengan taraf signifikan $\alpha=0,05$. Uji homogenitas tidak dilakukan karena kelompok latihan sudah berasal dari populasi yang sama.

\section{HASIL DAN PEMBAHASAN (70\%)}

\section{Hasil Penelitian}

1. Pre Test dan Post Test Kemampuan Three Point Shoot

Pengukuran pre test kemampuan three point shoot dilakukan sebelum diberikan perlakuan, yaitu bentuk latihan plyometrics kepada sampel 10 atlet putra Dharma Muda Dharmasraya. Dari hasil pengukuran pre test kemampuan three point shoot tersebut didapat, yaitu nilai minimal 12 dan nilai maksimal 22. Kemudian diperoleh juga mean sebesar 16,1 dan standar deviasi sebesar 3,314. Kemudian pengukuran post test kemampuan three point shoot dilakukan setelah mendapatkan perlakuan, yaitu bentuk latihan plyometrics selama 16 kali pertemuan kepada sampel 10 atlet putra Dharma Muda Dharmasraya. Dari hasil pengukuran post test kemampuan three point shoot tersebut didapat, yaitu nilai minimal 19 dan nilai maksimal 29. Kemudian diperoleh juga mean sebesar 22,8 dan standar deviasi sebesar 3,735.

Tabel 2. Distribusi Frekuensi Peningkatan Kemampuan Three Point Shoot

\begin{tabular}{|c|c|c|c|c|c|}
\hline \multirow{2}{*}{ No } & \multirow{2}{*}{ Kelas Interval } & \multicolumn{2}{|c|}{ Pre Test } & \multicolumn{2}{c|}{ Post Test } \\
\cline { 3 - 6 } & $\begin{array}{c}\text { Absolut } \\
(\mathrm{Fa})\end{array}$ & Relatif (\%) & $\begin{array}{c}\text { Absolut } \\
(\mathrm{Fa})\end{array}$ & Relatif (\%) \\
\hline 1 & $1-11$ & 0 & $0,00 \%$ & 0 & $0,00 \%$ \\
\hline 2 & $12-22$ & 10 & $100 \%$ & 5 & $50 \%$ \\
\hline 3 & $23-33$ & 0 & $0,00 \%$ & 5 & $50 \%$ \\
\hline 4 & $34-45$ & 0 & $0,00 \%$ & 0 & $0,00 \%$ \\
\hline & Jumlah & 10 & $100 \%$ & 10 & $100 \%$ \\
\hline
\end{tabular}

Berdasarkan pada tabel 2 distribusi frekuensi pre test dari 10 atlet sampel, atlet memiliki skor kemampuan three point shoot dengan perolehan nilai berkisar antara 1-11 tidak ada $(0,00 \%)$. Seluruh atlet $(100 \%)$ memiliki skor kemampuan three point shoot dengan perolehan nilai berkisar antara 12-22, sedangkan atlet memiliki skor kemampuan three point shoot dengan perolehan nilai berkisar antara 23-33 dan 34-45 tidak ada (0,00\%).

Distribusi frekuensi post test dari 10 atlet sampel, atlet yang memiliki skor kemampuan three point shoot dengan perolehan nilai berkisar antara 1-11 tidak ada (0,00\%). 5 atlet (50\%) memiliki skor kemampuan three point shoot dengan perolehan nilai berkisar antara 12-22. 5 atlet (50\%) memiliki skor kemampuan three point shoot dengan perolehan nilai berkisar 
antara 23-33. Sedangkan atlet memiliki skor kemampuan three point shoot dengan perolehan nilai berkisar antara $34-45$ tidak ada (0,00\%).

2. Uji Normalitas

Uji normalitas dilakukan dengan menggunakan uji lilieforsdengan taraf nyata $(\alpha)=0,05$. Kriteria pengujiannya adalah bahwa tolak hipotesis nol jika Lobservasi (Lo) yang diperoleh dari data pengamatan melebihi Ltabel (Lt) dan sebaliknya terima hipotesis nol apabila Lobservasi (Lo) yang diperoleh lebih kecil dari Ltabel (Lt) secara sederhana dapat digunakan rumus sebagai berikut:

Ha ditolak jika, Lobservasi (Lo) > Ltabel (Lt)

Ha diterima jika, Lobservasi (Lo) < Ltabel (Lt)

Tabel 3. Uji Normalitas Data Kemampuan Three Point Shoot

\begin{tabular}{|c|c|c|c|c|c|}
\hline No & Variabel & N & Lo & Lt & Distribusi \\
\hline 1 & $\begin{array}{c}\text { Kemampuan Three Point } \\
\text { Shoot (Pre Test) }\end{array}$ & 10 & 0,2293 & 0,258 & Normal \\
\hline 2 & $\begin{array}{c}\text { Kemampuan Three Point } \\
\text { Shoot (Post Test) }\end{array}$ & 10 & 0,1844 & 0,258 & Normal \\
\hline
\end{tabular}

Tabel 3 menunjukkan bahwa hasil pengujian untuk pengukuran pre test kemampuan three point shoot skor Lo $=0,2293$ dengan $n=10$, sedangkan Ltabel pada taraf pengujian signifikan $\alpha=0,05$ diperoleh 0,258 yang lebih besar dari Lo. Sehingga disimpulkan bahwa skor kemampuan three point shoot berasal dari populasi yang berdistribusi normal dan dapat digunakan untuk pengujian hipotesis penelitian.

Untuk pengukuran post test kemampuan three point shoot skor Lo $=0,1844$ dengan $\mathrm{n}=10$, sedangkan Ltabel pada taraf pengujian signifikan $\alpha=0,05$ diperoleh 0,258 yang lebih besar dari Lo. Sehingga disimpulkan bahwa skor kemampuan threepoint shoot berasal dari populasi yang berdistribusi normal dan dapat digunakan untuk pengujian hipotesis penelitian.

3. Pengujian Hipotesis

Hipotesis yang diajukan adalah terdapat pengaruh latihan dari latihan plyometrics terhadap peningkatan kemampuan three point shoot pada atlet putra Dharma Muda Dharmasraya. Berdasarkan analisis komparasi dengan rumus uji beda mean (uji t) yang dilakukan maka diperoleh hasil analisis uji beda mean (uji t) sebagai berikut:

Tabel 4. Rangkuman Hasil Pengujian Hipotesis

\begin{tabular}{|c|c|c|c|c|c|c|}
\hline \multicolumn{2}{|c|}{ Variabel } & $\begin{array}{c}\text { Rata- } \\
\text { rata }\end{array}$ & $\mathrm{N}$ & $\begin{array}{c}\text { thitun } \\
\mathrm{g}\end{array}$ & ttabel & Keterangan \\
\hline $\begin{array}{c}\text { Kemampuan } \\
\text { Three Point }\end{array}$ & $\begin{array}{c}\text { Pre } \\
\text { Test }\end{array}$ & 16,1 & & & & \\
\hline
\end{tabular}




\begin{tabular}{|c|c|c|c|c|c|c|}
\hline Shoot & $\begin{array}{c}\text { Post } \\
\text { Test }\end{array}$ & 22,8 & 10 & 10,30 & 2,26 & Signifikan \\
\hline
\end{tabular}

Tabel 4 menunjukkan besar pengaruh latihan plyometrics terhadap peningkatan kemampuan three point shoot atlet putra Dharma Muda Dharmasraya dengan rata-rata pre test sebesar 16,1 dan post test nya meningkat menjadi 22,8 (meningkat 6,7). Kemudian hasil analisis uji beda mean (uji t) sebesar thitung 10,30 sedangkan ttabel sebesar 2,26 dengan taraf signifikan $\alpha=0,05$ dan $n=10$. Berdasarkan pengambilan keputusan di atas maka thitung > ttabel $(10,30>2,26)$. Dapat dikatakan bahwa terdapat pengaruh latihan plyometrics yang berarti terhadap peningkatan kemampuan three point shoot atlet putra Dharma Muda Dharmasraya.

\section{Pembahasan}

Berdasarkan hasil penelitian yang dilakukan di lapangan, membuktikan bahwa terdapat pengaruh latihan plyometrics terhadap peningkatan kemampuan three point shoot atlet putra Klub Dharma Muda Dharmasraya. Sebelum diberikan perlakuan terhadap sampel, terlebih dahulu diketahui kemampuan maksimal atlet pada setiap bentuk latihan, kemudian dilakukan tes awal. Berdasarkan hasil tes tersebut ternyata kemampuan three point shoot diperoleh rata-rata pada saat pre test yaitu sebesar 16,1. Namun setelah diberikan perlakuan dengan latihan plyometrics maka terjadi peningkatan dengan rata-rata menjadi 22,8.

Hal ini diperkuat setelah dilakukan uji t, dimana diperoleh hasil thitung sebesar 10,30 yang lebih besar dari ttabel dalam taraf $\alpha=0,05$ sebesar 2,26. Dengan hasil penelitian ini berarti hipotesis yang diajukan dapat diterima kebenarannya, dalam kalimat lain dapat disimpulkan bahwa latihan plyometrics memberikan pengaruh yang signifikan terhadap peningkatan kemampuan three point shoot atlet putra Dharma Muda Dharmasraya.

Plyometrics merupakan latihan yang dilakukan untuk meningkatkan daya ledak otot yang sangat dibutuhkan dalam beberapa cabang olahraga, istilah ini sering digunakan dalam menghubungkan gerakan lompat yang berulang-ulang atau latihan untuk menghasilkan reaksi yang eksplosive.Tujuan latihan plyometrics adalah untuk merangsang berbagai macam perubahan dalam system syaraf otot, meningkatkan stabilitas kelompok-kelompok otot untuk merespon lebih cepat dan bertenaga dalam perubahan-perubahan singkat dan cepat pada panjang otot.

Pada cabang olahraga bolabasket, untuk menghasilkan kemampuan three point shoot yang baik sangat dibutuhkan unsur daya ledak otot. Apabila seseorang pemain memiliki daya ledak otot yang baik, maka dapat membantu kecepatan gerak tangan untuk mengarahkan dan mengusahakan agar bola masuk ke sasaran serta membantu atlet melakukan tolakan lompatan pada saat melakukan three point shoot. Oleh karena itu sangat diperlukan latihan plyometrics dalam bolabasket agar mendapatkan daya ledak otot yang baik agar dapat melakukan teknikteknik dalam bolabasket salah satunya yaitu three point shoot.

Tidak terlepas dari hasil yang diperoleh pada penelitian ini, faktor-faktor yang berkaitan dengan proses latihan juga sangat mempengaruhi hasil yang dicapai, seperti intensitas, durasi, beban latihan, serta frekuensi dalam latihan itu sendiri. Karena masing-masing faktor tersebut turut berperan terhadap kelangsungan latihan yang terprogram.

\section{KESIMPULAN}


Berdasarkan hasil penelitian, maka penulis memberikan beberapa saran agar dapat membantu mengatasi masalah yang ditemui dalam peningkatan kemampuan three point shoot atlet putra Dharma Muda Dharmasraya yaitu: Bagi pelatih bolabasket Dharma Muda Dharmasraya untuk dapat menggunakan latihan plyometrics dalam meningkatkan kemampuan three point shoot atlet putra Dharma Muda Dharmasraya. Bagi atlet putra Dharma Muda Dharmasraya perlunya memperhatikan latihan plyometrics untuk dapat meningkatkan kemampuan three point shoot agar termotivasi dan lebih semangat dalam berlatih.

\section{DAFTAR PUSTAKA}

Afrizal, S. (2018).Dayaledak Otot Tungkai Dan Kelentukan Berkontribusi Terhadap Akurasi Shooting Sepakbola. Jurnal Performa Olahraga, 3(02), 81-81.

Ardigò, L. P., Kuvacic, G., Iacono, A. D., Dascanio, G., \& Padulo, J. (2018).Effect of heart rate on basketball three-point shot accuracy. Frontiers in physiology, 9, 75.

Asadi, A., de Villarreal, E. S., \& Arazi, H. (2015). The effects of plyometric type neuromuscular training on postural control performance of male team basketball players. The Journal of Strength \& Conditioning Research, 29(7), 1870-1875.

DARI, L. J. G. J. D., TUNGKAI, D. L. O., \& BASUKI, S. PENGARUH LATIHAN PLIOMETRIK MULTIPLE BOX TO BOX JUMPS WITH SINGLE LEG LANDING DAN SINGLE LEG BOUNDING TERHADAP KEMAMPUAN.

Dinata, N. (2019). Pengaruh Latihan Plyometrics Terhadap Kemampuan Long Passing Pemain Sepakbola. Jurnal Patriot, 1(2), 840-850.

Donie, D. Kontribusi Daya Ledak Otot Tungkai dan Koordinasi Mata Tangan terhadap Kemampuan Jump Shoot Atlet Bola Basket. Jurnal Patriot, 1(2), 786-798.

DZUL FIKRI, M. U. H. A. M. M. A. D. (2013). Pengaruh Pelatihan 3-Point 5-Post Drill' sterhadap Hasil 3-Point Shooting Padaclub Bolabasket Putrasma Negeri 1 Taman. Jurnal Kesehatan Olahraga, 1(2).

Ihsan, N., Zulman, Z., \& Adriansyah, A. (2018).Hubungan Daya Ledak Otot Tungkai dan Dayatahan Aerobik Dengan KemampuanTendangan Depan Atlet Pencak Silat Perguruan Pedang Laut Pariaman. Jurnal Performa Olahraga, 3(1), 1-6.

Khlifa, R., Aouadi, R., Hermassi, S., Chelly, M. S., Jlid, M. C., Hbacha, H., \& Castagna, C. (2010).Effects of a plyometric training program with and without added load on jumping ability in basketball players. The Journal of Strength \& Conditioning Research, 24(11), 2955-2961.

Leksono, I. A. R. A., Saichudin, S., \& Januarto, O. B. (2016). Pengembangan Model Latihan Pliometrik Three Point-shoot Bolabasket Menggunakan Stimulasi Pleksus Brakhialis pada Siswa Ekstrakurikuler di SMA. Jurnal Sport Science, 4(1), 43-48.

Lockie, R. G., Murphy, A. J., Callaghan, S. J., \& Jeffriess, M. D. (2014).Effects of sprint and plyometrics training on field sport acceleration technique. The Journal of Strength \& Conditioning Research, 28(7), 1790-1801.

Maidarman, M. (2017).Kontribusi Daya Ledak Otot Tungkai dan Kelentukan Pinggang terhadap Kemampuan Start Renang Gaya Bebas Atlet Womens Swimming Club. Jurnal Performa Olahraga, 2(01), 13-21.

Mardela, R. (2019). Pengaruh Latihan Kelincahan Terhadap Kemampuan Tendangan Sabit Atlet Pencak Silat Kuciang Putiah Harimau Campo. Jurnal Patriot, 1(1), 145-150.

Margono, M., Yagusta, R. A. B., \& Khuzaini, A. (2018). PENGARUH ANTARA POWER LENGAN, AKURASI DAN KOORDINASI MATA TANGAN TERHADAP KEBERHASILAN 3 POINT SHOOT PADA ATLET PUTRI BOLABASKET SKO RAGUNAN. Gladi: Jurnal Ilmu Keolahragaan, 9(1), 3547. 
Nuryadi, A. (2016). PENGARUH LATIHAN PLYOMETRICS TERHADAP PENINGKATAN KETERAMPILAN LAY-UP BOLABASKET. Wahana: Tridharma Perguruan Tinggi, 66(1), 1-5.

Oktavianus, I., Bakhtiar, S., \& Bafirman, B. (2018). Bentuk Latihan Pliometrik, Latihan Beban Konvensional Memberikan Pengaruh terhadap Kemamampuan Three Point Shoot Bolabasket. Jurnal Performa Olahraga, 3(01), 21-21.

Palar, C. M., Wongkar, D., \& Ticoalu, S. H. (2015). Manfaat latihan olahraga aerobik terhadap kebugaran fisik manusia. eBiomedik, 3(1).

Ramos, M., Yenes, R., Donie, D., \& Oktavianus, I. (2020).Kontribusi Daya Ledak Otot Tungkai dan Keseimbangan Terhadap Kemampuan Jump Shoot Bolabasket. Jurnal Patriot, 2(3), 837-847.

Ridwan, M., \& Irawan, R. (2018). Validitas Dan Reliabilitas Tes Kondisi Fisik Atlet Sekolah Sepakbola (Ssb) Kota Padang " Battery Test Of Physical Conditioning " . Jurnal Performa Olahraga, 3(02), 90-90.

Ryan Malta, A., Yarmani, Y., \& Ari, S. STUDI KEMAMPUANTHREE POIN SHOOT BOLA BASKET PUTRA PADA CLUBBOLA BASKET KOTA BENGKULUTAHUN 2018 2019(Doctoral dissertation, UNIVERSITAS BENGKULU).

Santos, E. J., \& Janeira, M. A. (2008).Effects of complex training on explosive strength in adolescent male basketball players. The Journal of Strength \& Conditioning Research, 22(3), 903-909.

Soniawan, V., \& Irawan, R. (2018).Metode Bermain Berpengaruh Terhadap Kemampuan Long Passing Sepakbola. Jurnal Performa Olahraga, 3(01), 42-42.

Wulandari, M., \& Umar, U. (2020). Pengaruh Latihan Air Alert Terhadap Kemampuan Jump Shoot Pemain Bolabasket Klub Andromeda Padang. Jurnal Patriot, 2(2), 389-398.

Yenes, R. Pengaruh Latihan dengan Metode Massed Practice dan Distributed Practice Terhadap Kemampuan Three Point Shoot Bolabasket.

Yenes, R., Syahara, S., \& Kiram, Y. (2018).Pengaruh Daya Ledak Otot Tungkai dan Keseimbangan terhadap Kemampuan Jump Shoot Atlet Bolabasket FIK UNP. 